\title{
Polycrystalline SiC as source material for the growth of fluorescent SiC layers
}

Kaiser, M.; Hupfer, T.; Jokubavicus, V.; Schimmel, S.; Syväjärvi, M.; Ou, Yiyu; Ou, Haiyan; Linnarsson, M. K.; Wellmann, $P$.

Publication date:

2012

Link back to DTU Orbit

Citation $(A P A)$ :

Kaiser, M., Hupfer, T., Jokubavicus, V., Schimmel, S., Syväjärvi, M., Ou, Y., Ou, H., Linnarsson, M. K., \& Wellmann, P. (2012). Polycrystalline SiC as source material for the growth of fluorescent SiC layers. Abstract from European Conference on Silicon Carbide and Related Materials (ECSCRM 2012), Saint-Petersburg, Russian Federation.

\section{General rights}

Copyright and moral rights for the publications made accessible in the public portal are retained by the authors and/or other copyright owners and it is a condition of accessing publications that users recognise and abide by the legal requirements associated with these rights.

- Users may download and print one copy of any publication from the public portal for the purpose of private study or research.

- You may not further distribute the material or use it for any profit-making activity or commercial gain

- You may freely distribute the URL identifying the publication in the public portal 


\title{
Polycrystalline SiC as source material for the growth of fluorescent SiC layers
}

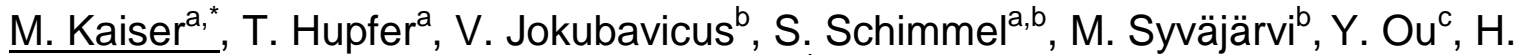 \\ $\mathrm{Ou}^{\mathrm{c}}$, M. K. Linnarsson ${ }^{\mathrm{d}}$ and P. Wellmann ${ }^{\mathrm{a}}$
}

Email: michl.kaiser@ww.uni-erlangen.de

${ }^{a}$ Department of Materials Science 6, University of Erlangen-Nuremberg, Martensstr. 7, 91058 Erlangen, Germany

${ }^{\mathrm{b}}$ Department of Physics, Chemistry and Biology, Linköping University, SE-58183, Linköping, Sweden

${ }^{\mathrm{c}}$ Department of Photonics Engineering, Technical University of Denmark, Denmark

d Integrated Devices and Circuits, KTH Royal Institute of Technology, Electrum 229, SE-164 40, Kista, Sweden

The emission of donor-acceptor-pair recombination in $\mathrm{SiC}$ is well known [1,2]. Especially nitrogen and boron co-doped $6 \mathrm{H}$-SiC layers with $\mathrm{B}$ concentrations of more than $10^{18} \mathrm{~cm}^{-3}$ show high internal quantum efficiency with the emission peak at about $580 \mathrm{~nm}$. The Fast Sublimation Growth Process (FSGP) is a proven technique to produce thick fluorescent $\mathrm{SiC}$ (f-SiC) layers of high crystallinity at high growth rates [3] which may be used for the fabrication of a white light emitting diode (LED) structure $[4,5]$ based on a blue InGaN LED grown on the yellow fluorescing SiC substrate. In this work we have investigated the properties of the polycrystalline SiC source materials grown by the PVT method and the impact of the grain properties (grain size, grain polytype and crystallographic grain orientation) on the growth rate during FSGP.

As source material nitrogen and boron co-doped polycrystalline SiC was grown using the PVT technique. Therefore $\mathrm{B}$, in the form of $\mathrm{B}_{4} \mathrm{C}$, was mixed into the $\mathrm{SiC}$ powder source with concentrations of $10 \mathrm{ppm}, 50 \mathrm{ppm}$ and $100 \mathrm{ppm}$, respectively. Gaseous nitrogen added to the chamber acted as continuous donor supply. The flux was fixed to $10 \mathrm{sccm}$ resulting in $\mathrm{n}$-type samples for each $\mathrm{B}$ concentration run. The growth runs were carried out at temperatures exceeding $2100^{\circ} \mathrm{C}$ under argon atmosphere at 35 mbar. The supersaturation of the gas species at the top inside a graphite crucible lead to the nucleation of the latter on an isostatically pressed highly purified graphite plate resulting in fine grains of different polytypes (Fig.1 a). During growth successive grain size enlargement can be observed leading to coarse grains in the range of several millimeters after approximately $20 \mathrm{~h}$ (Fig.1 b,c). In order to investigate the crystallographic orientation of different grains and their behavior during growth Laue photographs in back reflection geometry were taken from samples cut perpendicular to the z-axis. It was found that the $<0001>$ directions of the investigated grains inclines angles (off-axis angles, tilting) as low as $4^{\circ}$ up to $30^{\circ}$ in respect to the $z$-axis of the crucible, e.g. the symmetry axis of the setup. Their projections on the $x-y$-plane show, that they incline various angles in respect to the x-axis (Fig.2 a). Moreover it has to be stated that the grains do not grow textured and tilting does not appear towards the same crystallographic direction. Polytype identification was done using 
Raman spectroscopy in back scattering geometry. It pointed out that mainly the $15 \mathrm{R}$ modification forms under high tilt angles, e.g. more than $15^{\circ}$. Furthermore polytype switches appear within one grain.

As the polycrystalline source material consists of various polytypes and areas of different crystallographic orientation, we have investigated their influence on the sublimation epitaxy in terms of growth rate as well as the incorporation of dopants. By using a graphite mask between the polycrystalline source and the substrate only specific grains were allowed to sublime and therefore the influence of the tilt angle on the growth rate in the FSGP could be studied leading to different layer thicknesses for a fixed growth time (Fig.2 b). It is shown that the growth rate increases with increasing off-axis angle emerging a maximum at approximately $15^{\circ}$ followed by a decrease of less intense compared to the increase.

\section{Acknowledgment}

This work was supported by Bundesministerium für Bildung und Forschung (BMBF, contract 03SF0393), Ångpanneföreningen Research Foundation Swedish Energy Agency, Nordic Energy Research, Swedish Research Council (No. 2009-5307).

a)

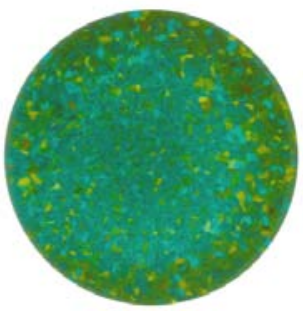

b)

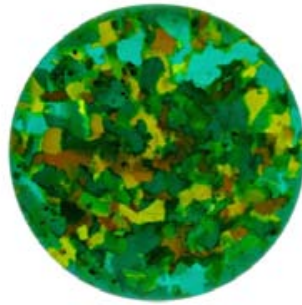

c)

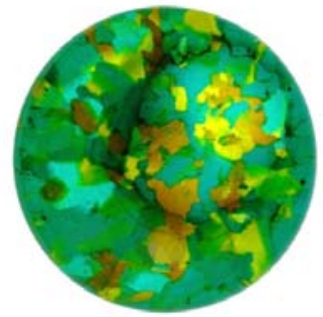

Fig. 1 a) Polycrystalline wafer after nucleation, b) after approximately $10 \mathrm{~h}$ and c) approximately $20 \mathrm{~h}$ of growth showing continuous grain size enlargement. The diameter of the wafers is $50 \mathrm{~mm}$.

a)

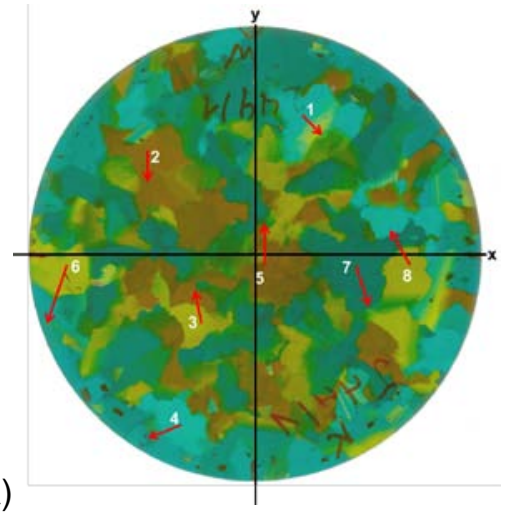

b)

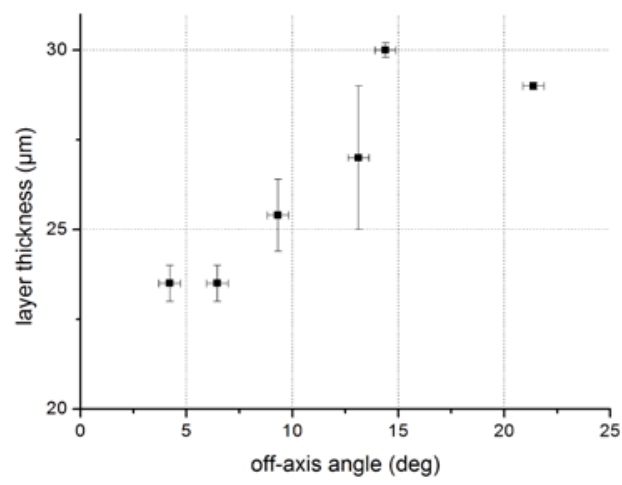

Fig. 2 a) Projection of the $<0001>$ directions (red arrows) on the $x-y$-plane, b) layer thickness vs. off-angle for isolated grains used as source in the FSGP.

\section{References}

[1] M. Ikeda, H. Matsunami, T. Tanaka, J. Lumin. 20, 111 (1979)

[2] M. Ikeda, H. Matsunami, T. Tanaka, Phys. Rev. B 22, 2824 (1980)

[3] V. Jokubavicius et al. Thin Solid Films (2011), doi: 10.1016/j.tsf.2011.10.176

[4] S. Kamiyama et al., J. Appl. Phys. 99, 093108 (2006)

[5] S. Murata et al., Mat. Sci. Forum 556, 335 (2007) 